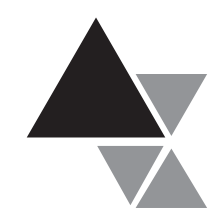

\title{
FATORES ANTINUTRICIONAIS EM ALIMENTOS: REVISÃO
}

\author{
Clícia Maria de Jesus Benevides ${ }^{1}$, Mariana Vasconcelos Souza ${ }^{2}$, \\ Raquel Dias Barros Souza ${ }^{2}$, Mariângela Vieira Lopes ${ }^{1}$
}

Os alimentos, além de apresentarem substâncias nutritivas essenciais para o desenvolvimento do organismo, podem também conter uma variedade de fatores antinutricionais, como os inibidores de proteínas, oxalatos, taninos, nitritos, dentre outros, assim denominados, devido ao fato de interferirem na absorção de nutrientes, podendo acarretar danos à saúde quando ingeridos em altas quantidades. Assim, esse artigo tem como objetivo discutir as possíveis consequências dos fatores antinutricionais em alimentos, assim como os efeitos do processamento sobre essas substâncias e apresentar estudos biológicos sobre os mesmos.

Palavras-chave: fatores antinutricionais, fitatos, oxalatos, taninos.

\section{ANTINUTRITIONAL FACTORS IN FOODS: A REVIEW}

The foods also give nutrients essential for the development of the organism, may also contain a variety of antinutritional factors such as inhibitors of protein, oxalates, tannins, nitrites, and others, so named due to the fact interfere with the absorption nutrients, causing damage to health when ingested in large quantities. Thus, this article aims to discuss the possible consequences of anti-nutritional factors in food, as well as the process effects of these substances and present biological studies about them.

Key-words: antinutritional factors, phytates, oxalates, tannins.

\footnotetext{
${ }^{1}$ Departamento Ciências da Vida, Universidade do Estado da Bahia (UNEB), Salvador, Bahia. Correspondência: Rua Marechal Andrea, 210, Ed. Cidade de Ouro Preto, Apto 202, Pituba, Salvador, Bahia. Tel. (71) 8775-8914.CEP 41810-105. E-mail: cbenevides@uneb.br

${ }^{2}$ Nutricionista.
} 


\section{INTRODUÇÃO}

O termo "fator antinutricional" tem sido usado para descrever compostos ou classes de compostos presentes numa extensa variedade de alimentos de origem vegetal, que quando consumidos, reduzem o valor nutritivo desses alimentos. Eles interferem na digestibilidade, absorção ou utilização de nutrientes e, se ingeridos em altas concentrações, podem acarretar efeitos danosos à saúde ${ }^{[1]}$, como diminuir sensivelmente a disponibilidade biológica dos aminoácidos essenciais e minerais, além de poder causar irritações e lesões da mucosa gastrintestinal, interferindo assim, na seletividade e eficiência dos processos biológicos ${ }^{[2]}$.

O conhecimento da presença de fatores antinutricionais e/ou tóxicos, que possam afetar o valor nutricional de hortaliças se faz cada vez mais necessário, pois a busca por alimentos saudáveis tem aumentado, especialmente na população brasileira. Tem-se assim, por exemplo, os taninos que tem habilidade em precipitar proteínas, os fitatos que podem formar complexos com proteínas e minerais e os oxalatos que podem precipitar com o cálcio, formando cristais insolúveis e cálculos renais nos indivíduos ${ }^{[3]}$.

Nos grãos das leguminosas verifica-se a ocorrência natural de inibidores de enzimas proteolíticas, como por exemplo, a tripsina. A ação destes inibidores no trato gastrintestinal leva à redução da disponibilidade dos aminoácidos. No entanto, na nutrição humana algumas dessas substâncias antinutricionais apresentam pequeno impacto, pois são termolábeis e geralmente são destruídas nas condições normais de preparo, doméstico ou industrial, dos alimentos ${ }^{[4]}$. Outrossim, a utilização cada vez maior de alimentos in natura ou o uso de baixas temperaturas de cozimento podem expor a população aos efeitos deletérios desses antinutrientes.

Os compostos fenólicos possuem a capacidade antioxidante e, portanto, podem assumir papel relevante na diminuição do risco de doenças cardiovasculares, alguns tipos de câncer, Mal de Alzheimer e Parkinson. No entanto, entre os compostos fenólicos, os taninos são considerados como antinutrientes por causa do efeito adverso na digestibilidade da proteína ${ }^{[5]}$.
Os fitatos representam uma classe complexa de componentes naturais que ocorrem principalmente em cereais e leguminosas e que afetam as suas propriedades funcionais e nutricionais. Os fitatos são sais do ácido fítico (mioinositol do ácido hexafosfórico - $\mathrm{C}_{6} \mathrm{H}_{18} \mathrm{O}_{24} \mathrm{P}$ ). Nutricionalmente, a presença de fitato é desfavorável, pois ocasiona a formação de complexos insolúveis com minerais e proteínas, reduzindo a biodisponibilidade desses nutrientes [6]. O efeito tóxico do ácido oxálico no organismo deve-se à formação de oxalato de cálcio na urina e ao aumento do risco de formação de cálculos renais, pois o oxalato de cálcio é pouco solúvel na urina e diminui a disponibilidade do cálcio para realização de numerosos processos fisiológicos. $O$ oxalato está presente em grande quantidade nos alimentos de origem vegetal, sendo o espinafre e o ruibarbo considerados alimentos de alto risco, pois apresentam grande concentração de oxalato biodisponível ${ }^{[7]}$.

Os nitratos estão presentes em todas as plantas e são fontes essenciais de nitrogênio para o seu crescimento normal. No ser humano, interfe no metabolismo da vitamina A e nas funções da glândula tireóide, podendo sofrer redução a nitrito no organismo e, após absorvidos, originar cianoses devido à formação de metamioglobina; ou ainda, reagir com aminas secundárias e terciárias formando composto N-nitrosos, potencialmente carcinogênicos ${ }^{[7,8]}$.

Portanto, em decorrência da busca cada vez mais frequente de conhecimentos com relação à presença e efeitos dessas substâncias nos alimentos por profissionais da área de saúde, além da população em geral, este artigo tem como objetivo discutir as possíveis consequências dos fatores antinutricionais em alimentos, assim como os efeitos do processamento sobre essas substâncias e apresentar estudos biológicos sobre os mesmos.

\section{FATORES ANTINUTRICIONAIS POLIFENÓIS (TANINOS)}

Polifenóis são substâncias naturais encontradas em plantas, como exemplo têm-se os flavonóides, taninos, lignanas, derivados do ácido caféico, dentre outras. Muitas destas substâncias são classificadas como antioxidantes naturais e possuem propriedades terapêuticas, estando presentes em alimentos e plantas medicinais ${ }^{[9]}$. 
Entre os compostos fenólicos, os taninos são considerados como antinutrientes por causa do efeito adverso na digestibilidade da proteína ${ }^{[5,10]}$. Nas dietas para seres humanos e espécies de animais monogástricos, taninos podem reduzir a digestibilidade da proteína, carboidratos e minerais; diminuir a atividade de enzimas digestivas, além de causar danos à mucosa do sistema digestivo ou exercer efeitos tóxicos sistêmicos ${ }^{[1]}$.

Os taninos são metabólitos secundários presentes em plantas e, geralmente, divididos em dois tipos: hidrolisáveis (galotaninos, elagitaninos) e condensados (não hidrolisáveis), formados por polímeros de proantocianidinas. Os taninos galotaninos, encontrados na maioria dos frutos como caqui e banana, são polímeros do ácido gálico. Já os taninos elagitaninos são formados por ácido elágico, composto utilizado no tratamento preventivo de câncer e amplamente encontrado em frutas vermelhas (morango, framboesa e amora). Por sua vez, os taninos condensados são responsáveis por determinadas características como adstringência e precipitação de proteínas e são encontrados em cascas de árvores (acácias) e em folhas ${ }^{[12]}$.

As principais características dessa classe de compostos são: a massa molecular (0,5 a $20 \mathrm{kDa})$; solubilidade em água; presença de grupos hidroxilafenólicos, que permite a formação de ligações cruzadas estáveis com proteínas; capacidade de combinação com celulose e pectina para formar complexos insolúveis ${ }^{[13]}$.

O conteúdo de taninos nas plantas pode variar de acordo com as condições climáticas e geográficas, maturação, dentre outros, e podem apresentar uma composição química variada, sendo muitas vezes, pouco conhecida. Na forma não oxidada, os taninos reagem com proteínas através de pontes de hidrogênio e/ou ligações hidrofóbicas. Quando oxidados, os taninos se transformam em quinonas, as quais formam ligações covalentes com alguns grupos funcionais das proteínas, principalmente os grupos sulfídricos da cisteína e $\omega$-amino da lisina ${ }^{[14]}$. A complexação dos taninos com as proteínas tornam-as insolúveis e inativam as enzimas. Essa complexação é a principal base do efeito biológico e é dependente do $\mathrm{pH}$ e envolve ligações hidrofóbicas e pontes de hidrogênio. Além disso, se ligam a outras macromoléculas como o amido causando dessa maneira a redução no valor nutricional dos alimentos ${ }^{[15]}$.

Em determinados alimentos, como as leguminosas, os taninos têm recebido atenção por causa de alguns efeitos prejudiciais à dieta, como na cor do alimento, devido às reações de escurecimento enzimático e diminuição da sua palatabilidade, devido à adstringência [2]. A adstringência é a sensação causada pela formação de complexos entre os taninos e as glicoproteínas salivares, o que pode aumentar a salivação e diminuir a aceitabilidade do alimento ${ }^{[6]}$.

Canniatti-Brazaca ${ }^{[16]}$ avaliou os teores de taninos em produtos de ervilha. O autor cita que duas amostras de ervilha (sopa liofilizada e enlatada) não apresentaram taninos e outras duas (sopa congelada e seca) não apresentaram quantidades elevadas $(0,19 \pm 0,0 \mathrm{mg} / \mathrm{g}$ e $0,12 \pm 0,0 \mathrm{mg} / \mathrm{g}$, respectivamente), considerando, portanto, que os taninos não são um fator que irá influenciar na diálise do ferro e no aproveitamento das proteínas quando a ervilha estiver nestas forma de consumo. Ferreira \& Arêas [17] estudaram a biodisponibilidade in vitro do cálcio de amaranto (Amaranth caudatus L.) antes e após extrusão e observaram que os níveis de taninos no amaranto cru $(1,31 \pm 0,23 \mathrm{mg} / \mathrm{g})$ e extrusado $(1,28 \pm 0,52 \mathrm{mg} / \mathrm{g})$ foram baixos e que não teriam impacto na biodisponibilidade do cálcio.

\section{NITRATOS E NITRITOS}

Nitratos $\left(\mathrm{NO}_{3}^{-}\right)$e nitritos $\left(\mathrm{NO}_{2}^{-}\right)$podem estar presentes naturalmente, nos alimentos de origem vegetal e animal e na água, em decorrência do uso de fertilizantes na agricultura ${ }^{[18]}$. As principais fontes de exposição alimentar a nitratos e nitritos incluem os vegetais, produtos cárneos, peixes e aves processados e defumados, aos quais se adicionam nitratos e/ ou nitritos, e ainda a água se esta for recolhida em locais onde exista contaminação por nitratos de origem agrícola. As plantas são a principal fonte de nitratos (80-90\%), enquanto os produtos processados e curados são a principal fonte de nitritos ${ }^{[19]}$. Estimase que as hortaliças, em particular as verdes folhosas, contribuam com mais de $70 \%$ do nitrato total ingerido. No entanto, as concentrações normais de nitrato e nitrito nos alimentos naturais dependem do uso de fertilizantes e das condições nas quais os alimentos são cultivados, colhidos e armazenados ${ }^{[8]}$. 
Nitratos e nitritos são substâncias que podem produzir efeito tóxico aos indivíduos pelo consumo de alimentos. Esses efeitos poderão ser severos ou não, dependendo da quantidade ingerida e da susceptibilidade do organismo. Os nitritos podem reagir com aminas secundárias e terciárias tanto in vivo como no próprio alimento, originando compostos $\mathrm{N}$-nitrosos (nitrosaminas) de elevado potencial carcinogênico, teratogênico e mutagênico ${ }^{[20]}$. No trato gastrintestinal, o nitrato pode ser convertido em nitrito pela ação de bactérias redutoras e este pode ser transformado em nitrosaminas no estômago ${ }^{[18]}$.

Além do risco de formação de nitrosaminas, a exposição a nitratos tem sido associada à síndrome da morte infantil súbita. Níveis altos de nitrato nos alimentos ou na água prejudicam o transporte de oxigênio no sangue, especialmente em crianças, devido ao surgimento de metamioglobinemia. Os nitratos são convertidos em nitritos, os quais convertem a hemoglobina a metamioglobina, o que afeta o transporte de oxigênio. Crianças com menos de 6 meses de vida são mais sensíveis à metamioglobinemia, que pode levar à anoxia e morte. Os casos de intoxicação estão geralmente relacionados com a ingestão de água

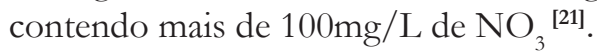

A avaliação periódica dos teores de nitratos e nitritos em alimentos deve ser realizada a fim de que a Ingestão Diária Aceitável (IDA) não seja ultrapassada, o que colocaria em risco a população. Os valores de IDA para nitratos e nitritos preconizados no Brasil e em todo Mercosul são os mesmos da Food and Agriculture Organization/World Health Organization (FAO/WHO), ou seja, de $0,06 \mathrm{mg} / \mathrm{kg} / \mathrm{dia}$ de nitrito (como íon) e de $3,7 \mathrm{mg} / \mathrm{kg} /$ dia para nitrato, ressaltando que a IDA não deve ser aplicada às crianças menores de 3 meses de idade. Alimentos destinados às crianças com menos de 6 meses de idade não podem conter nitrito como aditivo ${ }^{[22]}$.

\section{OXALATOS}

$\mathrm{O}$ oxalato, frequentemente encontrado em vegetais, não pode ser metabolizado pelos humanos e é excretado na urina. Segundo Chai \& Liebman ${ }^{\text {[23] }}$, cerca de $75 \%$ de todos os cálculos renais são compostos, principalmente, de oxalato de cálcio e a hiperoxalúria é um dos principais fatores de risco para esta doença porque o oxalato origina de uma combinação de absorção de oxalato da dieta e sintetizados endogenamente. A restrição da ingestão de oxalato na dieta tem sido sugerida como um tratamento para prevenir a nefrolitíase recorrente em alguns pacientes. O oxalato está presente em tecidos vegetais como uma combinação de fontes solúveis de oxalato de sódio e oxalato de potássio, bem como sais insolúveis de oxalato, tais como: oxalato de cálcio e de magnésio, sendo os oxalatos solúveis mais biodisponíveis. A elevada quantidade de oxalato na urina aumenta o risco da formação de cálculos de oxalato de cálcio nos rins, pois o oxalato de cálcio é pouco solúvel na urina ${ }^{[1]}$, podendo também causar irritações na mucosa intestinal ${ }^{[24]}$.

Alimentos com elevada quantidade de oxalatos, como o espinafre e a carambola (180-730 $\mathrm{mg} / 100 \mathrm{~g}$ ) não são recomendados para pessoas com tendência a formação de cálculos renais e com outros problemas relacionados a estes tipos de sais, como a artrite, o reumatismo e a gota ${ }^{[25,26]}$. Brogren \& Savage [27] investigaram os teores de fatores antinutrientes em espinafre comercializados na Nova Zelândia e encontram elevados níveis de oxalatos, sendo $736,6 \pm 20,4 \mathrm{mg} / 100 \mathrm{~g}$ de oxalato solúvel e 220,1 \pm 96 $\mathrm{mg} / 100 \mathrm{~g}$ de oxalato insolúvel.

Siener et al. ${ }^{[28]}$ determinaram o conteúdo de oxalato solúvel e total de vários tipos de cereais (arroz, trigo, centeio, aveia, cevada, milho) e produtos de moagem, pães, bolos e massas (farinhas, amido de milho, flocos de milho, dentre outros). O conteúdo de oxalato solúvel e total variou para os diferentes tipos de cereais de 3,2-148,9 mg/100g e 3,6-376,6 mg/100g, respectivamente e seus subprodutos, entre 0-131,2 $\mathrm{mg} / 100 \mathrm{~g}$ e 0-257,4 mg/100g, respectivamente. Para os autores, o maior teor de oxalato em grãos inteiros quando comparados aos produtos refinados sugere que o ácido oxálico está localizado, principalmente, nas camadas externas dos grãos de cereais. O maior teor de oxalato foi demonstrado para farelo de trigo $(457,4 \mathrm{mg} / 100 \mathrm{~g})$.

\section{FITATOS}

Os fitatos são derivados do ácido fítico ou ácido hexafosfórico mioinositol, com habilidade de formar quelantes com íons divalentes, tais como o cálcio e magnésio, formando complexos solúveis resistentes à ação do trato intestinal, que diminuem a disponibilidade desses minerais e, embora esse seja seu maior efeito, os fitatos também interagem com resíduos básicos das proteínas, participando 
da inibição de enzimas digestivas como a pepsina, pancreatina e a $\alpha$-amilase ${ }^{[6,10]}$.

Durante a estocagem, fermentação, germinação, processamento e digestão dos grãos e sementes, o ácido fítico pode ser parcialmente desfosforilado produzindo pentafosfato (IP5), tetrafosfato (IP4), trifosfato (IP3) e, possivelmente, inositol difosfato (IP2) e monofosfato (IP1), por ação de fitases endógenas ${ }^{[29]}$. Somente IP5 tem efeito negativo na biodisponibilidade de minerais, complexando o zinco e ferro, enquanto IP4 e IP3 não apresentam esta característica. Os demais compostos formados têm baixa capacidade de ligar-se a minerais ou os complexos formados são mais solúveis. O grau de ação inibitória dos fosfatos de inositol na absorção mineral depende do grau de fosforilação. Deste modo, a quantificação dos referidos compostos é de importância nutricional ${ }^{[30]}$.

Nos alimentos, sob condições naturais, o ácido fítico encontra-se carregado negativamente, o que lhe confere alto potencial para complexação com moléculas carregadas positivamente como cátions $\left(\mathrm{Zn}^{+2}, \mathrm{Fe}^{+2}, \mathrm{Fe}^{+3}, \mathrm{Mg}^{+2}\right.$ e $\left.\mathrm{Ca}^{+2}\right)$ e proteínas. Entretanto, o ácido fítico pode formar complexos com proteínas em $\mathrm{pH}$ ácido ou alcalino, desde que, as proteínas estejam abaixo ou acima do $\mathrm{pH}$ isoelétrico ${ }^{[31]}$.

Um importante fator na precipitação do fitato é o efeito sinérgico de dois ou mais cátions, os quais, quando presentes simultaneamente, podem atuar em conjunto, aumentando a quantidade de complexos fitato-metal precipitados ${ }^{[32]}$. Sangha et al. ${ }^{[33]}$ citaram que a razão molar fitato x cálcio:zinco é o melhor indicador da biodisponibilidade de zinco.

De acordo Domene et al. ${ }^{[34]}$ uma das formas de verificar a qualidade de cardápios é estimar a biodisponibilidade dos nutrientes presentes nas preparações, o que pode ser feito por meio do cálculo de razões molares fitato:zinco (fitato:Zn) e que, este efeito inibitório é potencializado quando há cálcio (Ca) na refeição. Assim, razões molares fitato:zinco e fitato x cálcio:zinco superiores, respectivamente, aos valores de 15 e 22 nas preparações, são indicadores de menor absorção de zinco e, consequentemente, limitadoras de sua biodisponibilidade. Segundo os autores, o zinco é um mineral envolvido em passos metabólicos relevantes para o bom funcionamento do sistema imune e para o crescimento e sua absorção intestinal pode ser prejudicada pela ação do fitato naturalmente presente nos alimentos diminuindo sua solubilidade intraluminal.

Ferreira \& Arêas [17] estudaram a biodisponibilidade do cálcio de amaranto e observaram

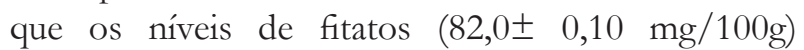
encontrados foram baixos quando comparados com outros alimentos tais como o trigo e triticale (170 e $190 \mathrm{mg} / 100 \mathrm{~g}$, respectivamente).

Nappi et al. ${ }^{[35]}$ determinaram os teores de ácido fítico em multimistura distribuída em Belo Horizonte no período de 10 meses. A média global

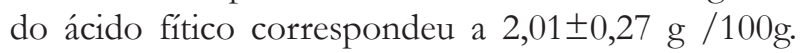
Assim, os autores constataram que os teores de ácido fítico encontrados estão cerca de vinte vezes acima do limite máximo permitido pelo Regulamento Técnico de Identidade e Qualidade de Mistura à Base de Farelos de Cereais, que é de $0,1 \mathrm{~g} / 100 \mathrm{~g}$ da amostra ${ }^{[36]}$.

\section{INIBIDORES DE PROTEASES}

Os inibidores de enzimas digestivas são encontrados com bastante frequência nos alimentos. Entre os mais conhecidos estão os inibidores de enzimas proteolíticas (tripsina, quimiotripsina) e amilolítica ( $\alpha$-amilase), sendo estas produzidas pelo pâncreas [37]. Em leguminosas, os inibidores de tripsina e lectinas são conhecidos como Aglutinina de Soja (SBA). A SBA, na soja in natura, é resistente às enzimas digestivas no trato gastrintestinal (GI) e se liga ao epitélio intestinal afetando as vilosidades, o que faz com que estas proteínas sejam detrimentais nos processos de digestão, absorção e utilização de nutrientes ${ }^{[38]}$.

Os inibidores de proteases na soja são constituídos pelo inibidor de tripsina Kunitz e pelo inibidor de tripsina e quimiotripsina Bowman-Birk. São classificados em duas principais categorias: os de alto peso molecular (cerca de $20.000 \mathrm{kDa}$ ), que apresentam duas pontes dissulfeto, 181 resíduos de aminoácidos e possuem especificidade primária para tripsina e os de peso molecular entre 6.000 e $10.000 \mathrm{kDa}$ com alta proporção de ligações dissulfeto, 71 resíduos de aminoácidos e capacidade para inibir tripsina e quimiotripsina em sítios de ligações independentes [39]. Cerca de $80 \%$ da inibição da atividade tríptica de grãos de soja é causada pela ação do inibidor de 
tripsina Kunitr: Estes antinutrientes apresentam especificidade de inibir as enzimas proteolíticas e, consequentemente, reduzem a digestão protéica de alimentos, proporcionando diminuição no ganho de peso e crescimento dos animais ${ }^{[40]}$.

Como citado anteriormente, entre os vários efeitos fisiológicos atribuídos aos fatores antitrípsicos, destacam-se a complexação com a tripsina e a quimiotripsina secretadas pelo pâncreas, impedindo a ação proteolítica dessas enzimas. Para tentar reverter a inibição da ação das enzimas proteolíticas, o pâncreas secreta mais enzimas, que por sua vez, são novamente inibidas, gerando uma sobrecarga pancreática e, consequentemente, uma hipertrofia desse órgão, reduzindo a ação digestiva em todo alimento presente na luz intestinal e, por conseguinte, prejudicando o desempenho do organismo ${ }^{[41]}$.

\section{GLICOSÍDEOS CIANOGÊNICOS}

Nas plantas, o ácido cianídrico ( $\mathrm{HCN}$ ) encontrase ligado a carboidratos denominados de glicosídeos cianogênicos, sendo liberado após sua hidrólise. Estes são produtos do metabolismo das plantas e, provavelmente, fazem parte do sistema de defesa contra herbívoros, insetos e moluscos ${ }^{[42]}$. Dentre os glicosídeos cianogênicos encontrados naturalmente em alimentos, tem-se a amigdalina, encontrada nas sementes de frutos da família das Rosáceas (pera, maçã, pêssego, cereja); a linamarina e lotaustralina, encontrados na mandioca e linhaça e a durrina, encontrada nos grãos jovens de sorgo. A concentração dos glicosídeos cianogênicos é variável nas diferentes espécies de plantas e numa mesma espécie varia dependendo do clima e outras condições que influenciam o crescimento da planta como adubação nitrogenada, deficiência de água e idade da planta, pois quanto mais nova e de crescimento rápido, maior será o teor em glicosídeos cianogênicos ${ }^{[43]}$.

Plantas cianogênicas, como a mandioca, apresentam compostos ciânicos e enzimas distribuídas em concentrações variáveis nas suas diferentes partes. Pela ruptura da estrutura celular da raiz, as enzimas presentes (linamarase; $\beta$-glicosidase), degradam estes compostos, liberando o $\mathrm{HCN}$, que é o princípio tóxico da mandioca e cuja ingestão ou mesmo inalação, representa sério perigo à saúde, podendo advir sintomas de intoxicação a depender da quantidade e tipo de alimento ingerido, podendo ocorrer casos extremos de envenenamento ${ }^{[4]}$.
Segundo Naves et al. ${ }^{[45]}$, o consumo de significativas doses de cianeto, advindas de alimentos ricos em glicosídeos cianogênicos e pobremente processados, pode resultar em intoxicações crônicas e agudas, causando anomalias tais como a doença de Konzo. O cianeto também apresenta notável poder tóxico pelo fato de ser um potente inibidor da citocromo oxidase, o que resulta no bloqueio da cadeia de transporte de elétrons durante o processo de respiração celular.

Estima-se que o consumo de alimento contendo ácido cianídrico (HCN), em uma concentração entre 0,5 a 3,5 mg de HCN por $\mathrm{kg}$ de peso corpóreo, possa levar $\mathrm{o}$ indivíduo à morte em poucos minutos. Entretanto, o risco de intoxicação pode ser minimizado a partir da utilização de processos de preparação, tais como: cozimento, fritura e secagem, que reduzem o teor desse composto no alimento. Esse efeito benéfico é resultante da remoção de glicosídeos cianogênicos, da inativação das $\beta$-glicosidases, ou de ambos ${ }^{[4]}$.

Em função do teor de HCN apresentado, as mandiocas são classificadas quanto à toxicidade em: mansas (menos de $50 \mathrm{mg} \mathrm{HCN} / \mathrm{Kg}$ de raiz fresca sem casca); moderadamente venenosa (50 a $100 \mathrm{mg}$ $\mathrm{HCN} / \mathrm{Kg}$ de raiz fresca sem casca) e venenosa ou brava (acima de $100 \mathrm{mg} \mathrm{HCN} / \mathrm{Kg}$ de raiz fresca sem casca). O conhecimento da toxicidade da planta limita o seu emprego, tanto na alimentação humana como na nutrição animal. As técnicas de processamento industrial para diminuição do princípio tóxico baseiamse na dissolução em água ou na volatilização, envolvendo processos como a maceração, remolho em água, fervura, torrefação ou fermentação das raízes de mandioca, ou ainda, a combinação desses processos ${ }^{[47]}$.

As consequências das intoxicações crônicas por glicosídeos cianogênicos presentes na mandioca são diversas. Quando envolve o sistema nervoso é chamada Neuropatia Atáxica Tropical (TAN), que é representada por mielopatia, atrofia óptica bilateral, surdez bilateral e polineuropatia ${ }^{[43]}$.

Chisté \& Cohen ${ }^{[48]}$ verificaram que farinhas de mandioca apresentaram concentrações de cianeto total, variando de 7,68 a 20,57 $\mathrm{mg} \mathrm{HCN} / \mathrm{Kg}$ nas farinhas do grupo seca e de 3,57 a 12,36 mg HCN/Kg na farinha do grupo d'água. Em um outro trabalho Chisté et al. ${ }^{[49]}$ quantificaram a concentração de 
cianeto total durante as etapas de produção da farinha de mandioca dos grupos seca e d'água. Em relação à farinha seca, a concentração de cianeto total na raiz de mandioca diminuiu de $160 \pm 11,8 \mathrm{mg} \mathrm{HCN} /$

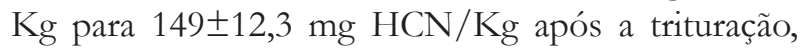
$68 \pm 2,5 \mathrm{mg} \mathrm{HCN} / \mathrm{Kg}$ após a prensagem e chegando a $5 \pm 0,2 \mathrm{mg} \mathrm{HCN} / \mathrm{Kg}$ no produto final, após o processo de torração. Na produção da farinha d'água, a raiz de mandioca apresentava teor de cianeto total de $321 \pm 21,6 \mathrm{mg} \mathrm{HCN} / \mathrm{Kg}$ e após a fermentação da raiz, o teor de cianeto total chegando a $64 \pm 2,3 \mathrm{mg}$ $\mathrm{HCN} / \mathrm{Kg}$. Após trituração e prensagem da massa fermentada, os valores diminuíram para $50 \pm 0,6$ e $36 \pm 0,4 \mathrm{mg} \mathrm{HCN} / \mathrm{Kg}$, respectivamente, obtendo-se no produto final a concentração de $9 \pm 0,1 \mathrm{mg} \mathrm{HCN} /$ $\mathrm{Kg}$, sendo evidenciado a eficiência do processo de destoxificação nos processamentos da mandioca.

\section{EFEITO DO PROCESSAMENTO NOS FATORES ANTINUTRICIONAIS}

Sabe-se que o tratamento térmico, dentre outras funções, é um método bastante utilizado para redução e/ ou inativação de substâncias indesejáveis em alimentos. Desse modo, vários estudos ${ }^{[17,23,45,46]}$ têm sido realizados para avaliar o efeito da temperatura nos teores dos fatores antinutricionais em produtos alimentícios.

Ferreira \& Arêas [17] estudaram o efeito da extrusão na biodisponibilidade do cálcio e de fatores antinutricionais em sementes de amaranto. Os autores observaram que não houve diferença significativa $(\phi<$ $0,05)$ nos níveis de taninos e fitatos entre o amaranto cru $(1305 \pm 0,23 \mathrm{mg} / 100 \mathrm{~g} ; 82,0 \pm 0,13 \mathrm{mg} / 100 \mathrm{~g})$ e extrusado (1284 $\pm 0,52 \mathrm{mg} / 100 \mathrm{~g} ; 82,0 \pm 010 \mathrm{mg} / 100 \mathrm{~g}$ ), respectivamente. Embora os resultados não tenham mostrado diferença significativa, nota-se uma redução nos níveis de taninos após a extrusão, mostrando o efeito do aquecimento nessas substâncias. Segundo Helbig \& Gigante ${ }^{[46]}$, durante o cozimento o fitato vai perdendo ligações fosfato transformando-se de um hexafosfato de inositol (fitato), em penta, tetra ou trifosfato perdendo, portanto, a sua capacidade inibitória.

Chai \& Liebman ${ }^{[23]}$ avaliaram o efeito de diferentes métodos de cozimento em vegetais no conteúdo de oxalato e observaram que a fervura promoveu uma maior redução no teor de oxalato (30$87 \%$ ) e foi mais eficaz do que cozinhar (5-53\%) e do que o forneamento (usado apenas para a batata, sem perda de oxalato). Os autores afirmam que o emprego de métodos de cozimento reduzem significativamente o oxalato e pode ser uma estratégia eficaz para diminuir oxalúria em indivíduos com predisposição para o desenvolvimento de pedras nos rins.

Naves et al. ${ }^{[45]}$ investigaram componentes antinutricionais e digestibilidade protéica em sementes de abóbora (Cucurbita maxima) submetidas a diferentes processamentos e observaram que houve redução nos teores de inibidores de proteínas na farinha de semente de abóbora (FSA) à medida que se aumentou o tempo de cozimento em água sob ebulição, variando-se os níveis de 9,51 a 5,97 UTI (Unidades de Tripsina Inibida)/mg. Além disso, notaram que os diferentes tipos de cozimento por 10 minutos (em água em ebulição e no vapor) não acarretaram diferença significativa nos níveis de inibidores de tripsina.

Delfino \& Canniatti-Brazaca ${ }^{[5]}$ avaliaram o efeito do processamento e armazenamento nos teores de taninos no feijão e observaram um decréscimo de $34,51 \%$ após o cozimento. De acordo os autores, isso se dá porque grande parte dos taninos é transportada por lixiviação à água de maceração. Após 6 meses de armazenamento ocorreu uma redução de $20,35 \%$ de taninos. Essa diminuição, provavelmente, ocorreu devido à oxidação e à menor solubilidade, decorrentes de seu maior grau de polimerização no tegumento ou pela lignificação dos cotilédones. Essas alterações que acontecem nos taninos contribuem para alterações físicas nos grãos.

Apesar de estudos mostrarem a eficiência do tratamento térmico na redução dos fatores nutricionais, esse processo apresenta algumas desvantagens como, por exemplo, a perda de nutrientes essenciais (vitaminas, aminoácidos, dentre outros) ${ }^{[37]}$. Outros métodos utilizados no processamento de alimentos também podem reduzir as concentrações dos fatores antinutricionais, tais como: a adição de água ao alimento, maceração na presença de sulfitos, trituração, descortiçamento de grãos, atmosfera controlada $\left(\mathrm{N}_{2}\right.$, etileno e etanol absoluto), tratamento enzimático, alta pressão hidrostática, dentre outros ${ }^{[2,6,46,50-52]}$. Severo et al. ${ }^{[50]}$ estudaram a destanização de frutos de jambolão mantidos sob temperatura ambiente e submetidos à atmosferas controladas $\left(20 \mathrm{kPa} \mathrm{CO}, 98 \mathrm{kPa} \mathrm{N}_{2}\right.$, etileno (100ppm) e 3,85 mL de etanol absoluto $\mathrm{L}^{-1}$ ) no período de 15 dias. Foi concluído que os frutos provenientes 
dos tratamentos com $\mathrm{N}_{2}$, etileno e etanol apresentaram os melhores resultados quanto à destanização, com aumento nos teores de acetaldeído e diminuição dos taninos solúveis e da adstringência. O princípio básico para a redução da concentração de taninos solúveis está baseado na indução da síntese de acetaldeído, que pode ser obtida pela diminuição de $\mathrm{O}_{2}$, pelo aumento de $\mathrm{CO}_{2}$ e/ou $\mathrm{N}_{2}$ ou pela aplicação de etanol. A efetividade desses métodos se deve ao fato de que esses tratamentos promovem a respiração anaeróbica nos frutos, e consequentemente há acúmulo de acetaldeído nos tecidos. Esse composto reage com o tanino solúvel (responsável pela adstringência), tornando-o insolúvel ou polimerizado ${ }^{[53]}$.

Teo et al. ${ }^{[51]}$ avaliaram as características físicoquímicas de concentrados protéicos obtidos da folha de mandioca por diferentes procedimentos. Os autores citam que os conteúdos de taninos foram semelhantes nos diversos tratamentos (cerca de 0,4 g ácido tânico/100g concentrado) e que os níveis dos mesmos reduziram de $37,70 \%$ a $50,82 \%$ em relação às folhas desidratadas. No caso do método de termocoagulação ácida, apesar da ausência de agitação, a redução dos taninos se deveu, provavelmente, à maceração em sulfito de sódio. A água, além de lixiviar substâncias, pode também facilitar a ação de outras substâncias na redução de fatores antinutrientes. Naves et al. ${ }^{[45]}$ citam que a enzima responsável pela degradação do substrato glicosídeo cianogênico é hidrolítica e, desta forma, necessita da presença da água para atuar.

Helbing \& Gigante ${ }^{[46]}$ detectaram $85 \mathrm{mg} /$ $\mathrm{kg}$ de $\mathrm{HCN}$ no pó da folha de mandioca seca o que corresponde a menos de $1 \%$ da concentração encontrada em folha de mandioca fresca (800-1600 $\mathrm{mg} / \mathrm{kg}$ base seca). Os autores citam que a melhor forma de manuseio da folha de mandioca, com vistas a obter uma maior redução do teor de ácido cianídrico, é a técnica de amassar e rasgar as folhas antes de as colocar para o processo de secagem. Essa medida promove o contato da enzima linamarase com os glicosídeos cianogênicos, linamarina e lotaustralina, decompondo-os a cianohidrinas até ácido cianídrico. Após o processo de secagem das folhas, a redução dos teores de ácido cianídrico atinge entre 70\% a 75\%.

Ma \& Wang [52] realizaram estudos com tratamentos enzimáticos e físicos para eliminar fatores antinutricionais (SBA) em soja. Segundo os autores a desglicosilação por enzimas individuais (tripsina, quimiotripsina, termolisina) reduziu a atividade da SBA até $21 \%$ e a combinação de enzimas, como por exemplo pepsina e pancreatina, tripsina e quimiotripsina, aumentou a desativação da SBA. Quando foi utilizado o aquecimento $\left(70-100{ }^{\circ} \mathrm{C}\right)$ no tratamento enzimático houve uma maior desativação da SBA, chegando a desativá-la completamente.

Torrezan et al. ${ }^{[6]}$ avaliaram os efeitos do tratamento sob alta pressão isostática (200 a 700 $\mathrm{MPa}$ ), considerado brando em relação ao tratamento térmico, sobre os fatores antinutricionais (fitatos e inibidor de tripsina) em isolado protéico de soja. De acordo os autores, há indícios que o tratamento sob alta pressão isostática seja eficiente para eliminar o fitato presente nas amostras de isolado protéico de soja, mas o mesmo não se mostrou efetivo para alterar os teores de inibidor de tripsina.

Santos [1] estudou o efeito do cozimento sobre alguns fatores antinutricionais (nitratos, taninos e oxalatos) em folhas de brócoli, couve-flor e couve e verificou queda nos teores de fatores antinutricionais com o aumento do tempo de cozimento, mostrando-se aceitáveis para o consumo. No entanto, os tratamentos utilizados não foram suficientes para reduzir os teores de polifenóis (taninos) das folhas de brócoli e couve a valores considerados adequados ao consumo humano, sugerindo a utilização conjunta de outra metodologia para a redução dos taninos presentes nesses vegetais. Ramírez-Cárdenas et al. ${ }^{[37]}$ observaram em alguns cultivares de feijão comum (Phaseolus vulgaris L.) que o cozimento promoveu acentuada redução no conteúdo de taninos; esta redução esteve na faixa de 64 a 83\% em relação aos feijões crus. De acordo os autores, os teores de fitatos (hexafosfato de inositol - IP6; pentafosfato de inositol - IP5; tetrafosfato de inositol - IP4; e trifosfato de inositol - IP3) também foram avaliados para os cultivares submetidos a diferentes processamentos. Após o cozimento observou-se uma redução de IP6 e um aumento de IP5, IP4 e IP3. A maior redução de IP6 para todos os cultivares foi obtida quando os feijões foram cozidos sem água de maceração e a menor redução quando foram cozidos sem maceração, mas tanto nos cultivares crus quanto cozidos, o IP6 representou a maior porcentagem dos fosfatos de inositol, sendo de 81 a $89 \%$ nos cultivares crus e de 58 a $75 \%$ nos cultivares cozidos. 
Del-Vechio et al. ${ }^{[54]}$ investigaram o efeito do tratamento térmico (cocção e tostagem) em sementes de abóboras (Cucurbita spp.) sobre os níveis de fatores antinutricionais e/ou tóxicos e verificaram que os tratamentos levaram à redução dos níveis de cianeto, sobretudo o cozimento. $\mathrm{O}$ cozimento causou maior redução nos níveis de cianeto comparado à tostagem, provavelmente, porque a enzima que degrada o glicosídeo cianogênico é hidrolítica e, portanto, necessita da presença de água para atuar. Assim, à medida que a semente foi sendo tostada, ela foi também perdendo água e diminuindo a ação da enzima. Além disso, a temperatura e o tempo de tostagem, maiores que o do cozimento, podem ter causado desnaturação da enzima. Os referidos autores também constataram que o cozimento acarretou diminuição nos níveis dos teores médios de inibidores de tripsina, apresentando-se mais eficiente que a tostagem.

Além da intervenção do processamento na redução dos fatores antinutricionais em alimentos, o desenvolvimento de novas linhagens de plantas também poderá contribuir na redução e/ou eliminação dessas substâncias. Foi realizado um estudo pelo Programa de Melhoramento da Qualidade e do Sabor da Soja do BIOAGRO (PMQS), da Universidade Federal de Viçosa (UFV), para o desenvolvimento de uma linhagem de soja com ausência de Inibidores de Tripsina Kunitz. (KTI) e lectina (LEC) em suas sementes. A retirada genética do KTI e LEC teve um impacto positivo na digestibilidade das proteínas da soja, no entanto, não melhorou a sua qualidade nutricional ${ }^{[39]}$.

\section{ESTUDOS BIOLÓGICOS COM RELAÇÃO AOS FATORES ANTINUTRICIONAIS}

Os efeitos deletérios dos fatores antinutricionais são confirmados ou não, após a realização de estudos biológicos, e a literatura apresenta vários ensaios ${ }^{[17,55-58]}$.

Cereda \& Lopes ${ }^{[56]}$ determinaram o potencial de intoxicação da linamarina extraída de mandioca em ratos e chegaram à conclusão de que a DL50 (Dose Letal para $50 \%$ de ocorrência) oral de linamarina extraída foi $324,86 \pm 1,5 \mathrm{mg} / \mathrm{kg} /$ peso, correspondendo a $35,35 \mathrm{mg}$ de $\mathrm{HCN} / \mathrm{kg}$ peso.
Weaver et al. ${ }^{[5]}$ estudaram a relação entre absorção de cálcio e presença de ácido oxálico em diversas fontes vegetais e mostraram que a absorção de cálcio de vegetais pobres em oxalato é semelhante à encontrada para o leite. Entretanto, quando se estudou o espinafre chinês, que tem $0,75 \mathrm{~g} / 100 \mathrm{~g}$ de oxalato, verificou-se que absorção de cálcio foi inferior aquela observada no leite como nos demais vegetais. Assim, a absorção de cálcio de vegetais sempre será influenciada pelo conteúdo em oxalato, que é um forte inibidor da absorção de cálcio. No caso dos vegetais chineses, preocupa-se com o excesso estequiométrico de oxalato em relação ao baixo conteúdo de cálcio, como é o caso das sementes de gergelim.

A biodisponibilidade do cálcio de amaranto foi avaliada em ensaio biológico por Ferreira \& Arêas ${ }^{[17]}$ antes e após o processo de extrusão. Ratos, alimentados por 28 dias com dietas em que o amaranto, antes ou após extrusão, era a única fonte de cálcio, foram comparados com animais em dieta controle com teor próximo de cálcio, oferecido na forma de carbonato de cálcio. De acordo os autores, a extrusão do amaranto aumentou a biodisponibilidade do cálcio. Possivelmente, o aquecimento durante a extrusão leva a uma série de transformações químicas em alguns agentes complexantes como os taninos, fitatos e oxalatos melhorando a biodisponibilidade do cálcio.

Sant'Ana et al. ${ }^{[57]}$ estudaram o valor nutritivo e fatores antinutricionais de multimisturas utilizadas como suplemento alimentar e foram verificados baixos teores residuais de inibidores de tripsina nas multimisturas. O estudo da razão molar cálcio:oxalato e da milimolar fitato x cálcio:zinco mostrou valores entre, respectivamente, 2,62:18,02 e 134:40,32. De acordo os autores, estes resultados indicam que as multimisturas têm teores consideráveis de oxalato e fitato, podendo interferir na biodisponibilidade dos minerais presentes. Assim, é de se esperar que as multimisturas que contêm estes compostos influenciem na biodisponibilidade de cálcio em função do conteúdo de oxalato e, tanto o fitato como seus vários isômeros, demonstram um efeito relevante na absorção mineral in vivo.

Jacinto [58] alimentou ratos recémdesmamados com farinha de linhaça crua como fonte exclusiva de proteínas a fim de avaliar seu efeito no crescimento dos mesmos. Os resultados foram 
um ganho de peso $73 \%$ inferior ao grupo padrão e redução no crescimento dos vilos intestinais de $35 \%$, afetando a digestibilidade in vitro e in vivo da fração globulina e detecção de fatores antinutricionais protéicos (inibidores de enzimas digestivas) na fração albumina, sendo estes considerados como possíveis fatores deletérios ao crescimento dos ratos em estudo. Gautam et al. ${ }^{[59]}$ citam que dietas contendo aminoácidos sulfurados melhoram a disponibilidade ferro e zinco. Assim, os autores investigaram a biodisponibilidade desses minerais em cereais (arroz e sorgo) cru e cozido na presença de alho e cebola, uma vez que estas espécies de vegetais são ricas em compostos sulfurados. Foi utilizado um método in vitro envolvendo um processo simulador de digestão gastrintestinal em que as amostras foram expostas à pepsina $(\mathrm{pH} 2,0)$ e incubadas a $37^{\circ} \mathrm{C}$ por $2 \mathrm{~h}$. Houve um aumento na biodisponibilidade do ferro e zinco nos cereias crus e cozidos, quando acrescidos de alho e cebola, variando de 9,4-65,9\%.

Brune et al. ${ }^{[39]}$ estudaram uma linhagem de soja sem Inibidor de Tripsina Kunitz (KTI) e Lectina (LEC) e avaliaram a qualidade nutricional da proteína e as alterações morfológicas no intestino de ratos Wistar alimentados com dietas à base de soja e de caseína. Os autores observaram que a atividade de inibição de tripsina nos genótipos KTI+LEC+(Variedade de soja comercial Monarca) foi cerca de 2,8 vezes a do genótipo KTI-LEC- (Isolinha de Monarca livre de KTI e LEC). Verificou-se, também, que os animais alimentados com a soja KTI+LEC+ apresentaram maior nível de alterações na morfologia das microvilosidades intestinais, quando comparados àqueles alimentados com a soja KTI-LEC- e que a retirada genética do KTI e LEC teve um impacto positivo na digestibilidade das proteínas da soja, no entanto não melhorou a sua qualidade nutricional.

\section{CONSIDERAÇÕES FINAIS}

Pelo exposto, observou-se que existem muitos trabalhos sobre os fatores antinutricionais em alimentos. Diversos são os efeitos negativos que são atribuídos a estas substâncias presentes naturalmente em alguns vegetais, tais como: redução na biodisponibilidade de minerais (oxalatos, fitatos), redução na digestibilidade de proteínas (taninos), inibição da citocromo oxidase (cianeto), formação de substâncias carcinogênicas (nitritos) e inibição de enzimas proteolíticas (inibidores de proteases). Apesar dos perigos que essas substâncias podem representar para os organismos, na maioria das vezes, não há problemas no consumo de alimentos contendo esses compostos, pois o próprio processamento, como a maceração, uso da atmosfera controlada, tratamento térmico, trituração, descortiçamento de grãos, tratamento enzimático, alta pressão isostática, dentre outros, poderá eliminá-los parcial ou totalmente. Estudos genéticos também têm sido realizados no desenvolvimento de variedades de vegetais com menor quantidade de determinados antinutrientes. As pessoas que possuem uma predisposição para desenvolver algumas enfermidades, como cálculo nos rins, devem ter atenção especial no consumo de alimentos contendo elevada quantidade de oxalatos. Sugere-se que os estudos continuem a serem realizados, principalmente, em alimentos de elevado consumo e os regionais. Estes últimos, na maioria das vezes, não se têm informações sobre a presença de fatores antinutricionais.

\section{REFERÊNCIAS}

1. Santos MAT. Efeito do cozimento sobre alguns fatores antinutricionais em folhas de brócoli, couve-flor e couve. Ciênc Agrotec. 2006;30(2):294-301.

2. Sgarbieri VC. Alimentação e Nutrição. São Paulo: Almed; 1987.

3. Mandel N. Mechanism of stone formation. Semin Nephrol. 1996;16(5):354-74.

4. Ojimelukwe PC, Onuoha CC, Obanu ZA. Effects of processing and in vitro proteolytic digestion on soybean and yambean hemagglutinins. Plant Foods Hum Nutr. 1995;47(4):293-99.

5. Delfino RA, Canniatti-Brazaca SG. Interação de polifenóis e proteínas e o efeito na digestibilidade protéica de feijão comum (Phaseolus vulgaris L.) cultivar Pérola. Ciênc Tecnol Aliment. 2010;30(2):308-12.

6. Torrezan R, Frazier RA, Cristianini M. Efeito do tratamento sob alta pressão isostática sobre os teores de fitato e inibidor de tripsina de soja. B CEPPA. 2010;28(2):179-86.

7. Lopes CO, Dessimoni GV, Costa MS, Vieira G, Pinto NAV. Aproveitamento, composição nutricional e antinutricional 
da farinha de quinoa (Chenopodium quinoa). Alim Nutr. 2009;20(4):669-675.

8. Guadagnin, SG. Avaliação do teor de nitrato em hortaliças folhosas produzidas por diferentes sistemas de cultivo [dissertação]. Campinas: Universidade Estadual de Campinas; 2004. 78 p.

9. $\mathrm{Xu} \mathrm{B}$, Chang SKC. Phenolic substance characterization and chemical and cell-based antioxidant activities of 11 lentils grown in the northern United States. J Agric Food Chem. 2010;58(3):1509-17.

10. Damodaran S, Parkin KL, Fennema OR. Química de Alimentos de Fennema. Porto Alegre: Artmed; 2010.

11. Sreerama YN, Neelam DA, Sashikala VB, Pratape VM. Distribution of nutrients and antinutrients in milled fractions of chickpea and horse gram: seed coat phenolics and their distinct modes of enzyme inhibition. J Agric Food Chem. 2010;58(7):4322-30.

12. Gilani GS, Cockell KC, Sepehr E. Effects of antinutritional factors on protein digestibility and amino acid availability in foods. J AOAC Int. 2005;88(3):967-87.

13. Reed JD. Nutritional toxicology of tannins and related polyphenols in forage legumes. J Anim Sci.1995;73(5):151628.

14. Sgarbieri VC. Proteínas em alimentos protéicos: propriedades, degradações, modificações. São Paulo: Livraria Varela; 1996.

15. Guzmán-Maldonado SH, Acosta-Gallegos J, ParedesLópez O. Protein and mineral content of a novel collection of wild and weed common bean (Phaseolus vulgaris L.). J Sci Food Agric. 2000;80(13):1874-81.

16. Canniatti-Brazaca SG. Valor nutricional de produtos de ervilha em comparação com a ervilha fresca. Ciênc Tecnol Aliment. 2006;26(4):766-71.

17. Ferreira TA, Arêas JAG. Calcium bioavailability of raw and extruded amaranth grains. Ciênc Tecnol Aliment. 2010;30(2):532-38.

18. Levallois P, Phaneuf D. Contamination of drinking water by nitrates: analysis of health risks. Can J Public Health. 1994;85(3):192-96.

19. Pennington JAT. Dietary exposure models for nitrates and nitrites. Food Control. 1998;9:385-95.

20. Araújo ACP, Midio AF. Nitratos e nitritos en alimentos infantilis industrializados y caseros. Alimentaria. 1990;27:69-75.

21. George M, Wiklund L, Astrup M, Pousette J, Thunholm $\mathrm{B}$, Saldeen $\mathrm{T}$ et al. Incidence and geographical distribution of sudden infant death syndrome in relation to content of nitrate in drinking water and groundwater levels. Eur J Clin Invest. 2001;31(12):1083-94.

22. Food and Agriculture Organization/World Health Organization. Technical Report Series 859 - Evaluation of certain food additives and contaminants. 44th report of the Joint FAO/WHO Expert Committee on Food Additives; 1996.

23. Chai W, Liebman M. Effect of different cooking methods on vegetable oxalate content. J Agric Food Chem. 2005;53(8):3027-30.

24. Krause MV, Mahan LK. Estado nutricional do indivíduo. In: Krause MV, Mahan LK (Org.). Alimentos, nutrição e dietoterapia. São Paulo: Roca; 2005. p. 192-236.

25. Moreira FG, Iervolino RL, Dall'orto SZ, Beneventi ACA, Filho JLO, Góis AFT. Intoxicação por carambola em paciente com insuficiência renal crônica: relato de caso. Rev Bras Ter Intensiva. 2010;22(4):395-98.

26. Massey LK. Food Oxalate: factors affecting measurement, biological variation, and bioavailability. J Am Diet Assoc. 2007;107(7):1191-94.

27. Brogren M, Savage GP. Bioavailability of soluble oxalate from spinach eaten with and without milk products. Asia Pac J Clin Nutr. 2003;12(2):219-24.

28. Siener R, Honow R, Voss S, Seidler A, Hesse A. Oxalate content of cereals and cereal products. J Agric Food Chem. 2006;54(8):3008-11.

29. Zhou JR, Fordyce EJ, Raboy V, Dickinson DB, Wong MS, Burns RA et al. Reduction of phytic acid in soybean products improves zinc bioavailability in rats. J Nutr.1992;122(12):2466-73.

30. Han O, Failla ML, Hill DA, Morris ER, Smith JC. Inositol phosphates inhibit uptake and transport of iron and zinc by a human intestinal cell line. J Nutr. 1994;124(4):580-87. 
31. Leal AS, Gonçalves CG, Vieira IFR, Cunha MRR, Gomes TCB, Marques FR. Avaliação da concentração de minerais e dos fatores antinutricionais fitato e oxalato em multimisturas da Região Metropolitana de Belo Horizonte/MG. Nutrire: Rev Soc Bras Alim Nutr. 2010;35(2):39-52.

32. Cheryan M. Phytic acid interactions in food systems. CRC Crit Rev Food Sci Nutr. 1980;13(4):297-35.

33. Sangha JK, Parmar AK, Sachdeva R. Mineral content of wheat cultivars with reference to their molar ratios. J Food Sci Technol. 1998;35(2):151-53.

34. Domene SMA, Pereira TC, Arrivillaga RK. Estimativa da disponibilidade de zinco em refeições com preparações padronizadas da alimentação escolar do município de Campinas. Rev Nutr. 2008;21(2):161-67.

35. Nappi GU, Ribeiro-Cunha MR, Coelho JV, Jokl L. Validação de métodos para determinação dos ácidos fítico e oxálico em multimistura. Ciênc Tecnol Aliment. 2006;26(4):811-820.

36. Brasil. Agência Nacional de Vigilância Sanitária. Resolução no 53, de 15 de junho de 2000. Dispõe sobre o Regulamento Técnico de Identidade e Qualidade de Mistura à base de Farelo de Cereais. Diário Oficial da União, Brasilia, 19 jun. 2000. Seção 1, p. 36.

37. Ramírez-Cárdenas L, Leonel AJ, Costa NMB. Efeito do processamento doméstico sobre o teor de nutrientes e de fatores antinutricionais de diferentes cultivares de feijão comum. Ciênc Tecnol Aliment. 2008;28(1):200-13.

38. Zang J, Li D, Piao X, Tang S. Effects of soybean agglutinin on body composition and organ weights in rats. Arch Anim Nutr. 2006;60(3):245-53.

39. Brune MFSS, Pinto MO, Peluzio MCG, Moreira MA, Barros EGB. Avaliação bioquímico-nutricional de uma linhagem de soja livre do inibidor de tripsina kunitz, e de lectinas. Ciênc Tecnol Aliment. 2010;30(3):657-63.

40. Monteiro MRP, Costa NMB, Oliveira MGA, Pires CV, Moreira MA. Qualidade protéica de linhagens de soja com ausência do inibidor de tripsina kunitz, e das isoenzimas lipoxigenases. Rev Nutr. 2004;17(2):195-205.

41. Opalinski M, Maiorka A, Cunha F, Martins da Silva EC, Borges SA. Adição de níveis crescentes de complexo enzimático em rações com soja integral desativada para frangos de corte. Arch Vet Sci. 2006;11(3):31-5.

42. Tokarnia CH, Peixoto PV, Brito MF, Duarte MD, Brust LAC Estudos experimentais com plantas cianogênicas em bovinos. Pesq Vet Bras. 1999;19(2):84-90.

43. Midio AF, Martins DI. Toxicologia de alimentos. São Paulo: Livraria Varela; 2000.

44. Chisté RC, Cohen KO, Mathias EA, Ramoa Junior AGA. Qualidade da farinha de mandioca do grupo seca. Ciênc Tecnol Aliment. 2006;26(4):861-64.

45. Naves LP, Corrêa AD, Santos CD, Abreu CMP. Componentes antinutricionais e digestibilidade protéica em sementes de abóbora (Cucurbita maxima) submetidas a diferentes processamentos. Ciênc Tecnol Aliment. 2010;30(Supl. 1):180-84.

46. Helbig E, Gigante DP. Análise dos teores de ácidos cianídrico e fítico em suplemento alimentar: multimistura. Rev Nutr. 2008;21(3):323-28.

47. Cagnon JR, Cereda MP, Pantarotto S. Cultura de tuberosas amiláceas latino-americanas. Cd-rom. Vol. 2. Série: Fundação Cargill; 2002.

48. Chisté RC, Cohen KO. Determinação de cianeto total nas farinhas de mandioca do grupo seca e d'água comercializadas na cidade de Belém-PA. RBTA. 2008;2(2):96-102.

49. Chisté RC, Cohen KO, Mathias EA, Oliveira SS. Quantificação de cianeto total nas etapas de processamento das farinhas de mandioca dos grupos seca e d'água comercializadas. Acta Amaz. 2010;40(1):221-26.

50. Severo J, Santos RS, Casaril J, Tiecher A, Silva JA, Rombaldi CV. Destanização e conservação de frutos de jambolão. Cienc Rural. 2010;40(4):976-82.

51. Teo CRPA, Prudencio SH, Coelho SRM, Teo MS. Obtenção e caracterização físico-química de concentrado protéico de folhas de mandioca. Rev Bras Eng Agríc Ambient. 2010;14(9):993-99.

52. Ma Y, Wang T. Deactivation of soybean agglutinin by enzymatic and other physical treatments. J Agric Food Chem. 2010;58(21):11413-419.

53. Edagi FK, Kluge RA. Remoção de adstringência de caqui: 
um enfoque bioquímico, fisiológico e tecnológico. Cienc Rural. 2009;39(2):585-94.

54. Del-Vechio G, Corrêa AD, Abreu CMP, Santos CD. Efeito do tratamento térmico em sementes de abóboras (Cucurbita spp.) sobre os níveis de fatores antinutricionais e/ou tóxicos. Ciênc Agrotec. 2005;29(2):369-76.

55. Weaver CM, Martin BR, Ebner, JS. Oxalic acid decreases calcium absorption in rats. J Nutr. 1987;117(11):1903-06.

56. Cereda MP, Lopes AM. Determinação do potencial de intoxicação em ratos, de linamarina extraída de mandioca. In: $\mathrm{V}$ SIMPÓSIO LATINO AMERICANO DE CIÊNCIA DE ALIMENTOS, 2003, Campinas. Anais... Campinas: Ed. UNICAMP. p. 48.

57. Sant'Ana LFR, Cruz ACR, Franceschini SCC, Costa NMB. Efeito de uma multimistura alimentar no estado nutricional relativo ao ferro em pré-escolares. Rev Nutr. 2006;19(4):445-54.

58. Jacinto KA. Efeito do consumo de farinha de linhaça (Linum usitatissimum) no crescimento de ratos Wistar e sua relação com a digestibilidade de globulinas e fatores antinutricionais protéicos nas albuminas dissertação.. Natal: Universidade Federal do Rio Grande do Norte; 2007. 92 p.

59. Gautam S, Platel K, Srinivasan K. Higher bioaccessibility of iron and zinc from food grains in the presence of garlic and onion. J Agric Food Chem. 2010;58(14):8426-29. 